\title{
O Brasildeutsch em enunciados no ato de cozinhar
}

\section{Brasildeutsch in enunciations in the cooking act}

\author{
Clarice Nadir von Borstel
}

\begin{abstract}
Resumo: O estudo em questão se faz sob a perspectiva da heterogeneidade linguística e dos recursos do uso da pragmática, descrevendo o léxico no ato de cozinhar em expressões do Brasildeutsch - que assume uma dupla função dentro do sistema diglóssico. Apresenta-se o léxico utilizado em interações comunicativas de falantes de descendentes de alemães de uma tradição interlinguística do falar dialetal e cultural de seus antepassados. Assim, descrevem-se os itens lexicais que apresentam informações fonológica, morfossintática e semântico-pragmática no ato de cozinhar em expressões linguísticas, a partir dos valores sociais e, historicamente, constituídos na e pela linguagem de falantes bilíngues, quando utilizam a alternância lexical de dois códigos (o alemão e o português) na interação comunicativa, na comunidade de fala de Marechal Cândido Rondon, Paraná.
\end{abstract}

Palavras-chave: Léxico semântico-pragmático. Brasildeutsch. Comunidade de fala.

Abstract: This study is carried out according to the linguistic heterogeneity perspective and from the pragmatic usage resources, describing the lexicon used in the cooking act in Brasildeutsch expressions - which assumes a dual function within the diglossic system. The study presents the lexicon used in the communicative interactions between speakers of German descendants that have an interlinguistic tradition of dialectal and cultural inherited from their ancestors. Therefore the lexical items described are those that present phonological, morphosyntatic and semantic-pragmatic information in the cooking act in linguistic expressions, from social values and historically constituted in and through the language of bilingual speakers, when they use the lexical alternation of two codes (German and Portuguese) in communicative interactions, in the speech community of Marechal Cândido Rondon, Paraná.

Keywords: Semantic-pragmatic lexical. Brasildeutsch. Speech community.

\section{Introdução}

Os falares dialetais plurilíngues, no Brasil, são sensivelmente marcados pela heterogeneidade não funcional de seus elementos constitutivos e pelo atraso em face de descrições linguísticas. Essas descrições não estão coerentemente constituídas nacionalmente com relação à fala dos usuários em

\footnotetext{
* Doutora. Universidade Estadual do Oeste do Paraná - Unioeste. <clavon borstel@gmail.com>.
} 
suas interlocuções em comunidades de fala interétnicas, quando a variação e as mudanças linguísticas de um bilinguismo relativo e/ou societal estão muito presente no cotidiano de falantes em situação de linguagem herdada de seus antepassados.

Desta maneira, a forma que a palavra tem quando se fala o Brasildeutsch quanto à transformação do léxico da língua alemã para o português, quando da incorporação de argumentos internos semânticos e dos recursos dos atos de fala nas interlocuções entre os falantes. O estudo pode mostrar essa incorporação na designação terminológica por nominalização e/ou a forma nominalizada, podendo esta ser usada para a referência anafórica ao sintagma verbal e nominal correspondente, de modo que os falantes descendentes de alemães da comunidade de fala de Marechal Cândido Rondon, Paraná, incorporaram esses traços linguísticos da língua alemã na denominação terminológica do português. O conteúdo semântico-pragmático da vivência histórica e de experiência cultural desses descendentes, no sul do país, embora esteja consolidado nas formas materiais, encontra-se também generalizado e reflete-se nas formas por nominalização e nas verbais de interação comunicativa entre os usuários, quando há a solidariedade intercultural/linguística em comunidades de fala de dialetos da língua alemã e da variação do português.

É a partir da compreensão da palavra que resulta a interação que os indivíduos conseguem estabelecer entre o verbal e o não verbal, entre a palavra e o afetivo-emocional de aspectos socioculturais na comunicação entre as pessoas sob uma concepção semântica e pragmática.

É dessa forma que se pretende descrever o léxico de forma pragmática do falar português-alemão, que assume uma dupla função dentro do sistema diglóssico: o Brasildeutsch - o linguajar cotidiano do ato de cozer, em situações de expressões lexicais, mostrando a transferência semântica e a (re) interpretação pragmática do léxico da língua alemã sócio-histórica e cultural em interações comunicativas do dia a dia entre os falantes descendentes de alemães, nessa comunidade de fala do oeste paranaense.

\section{O léxico e as noções socioculturais da palavra no ato de cozinhar}

A cultura na e pela diferença da linguagem quanto às formas alimentares do cotidiano de um dado grupo social e cultural no qual muitas 
vezes são as mulheres que em geral se encarregam do trabalho cotidiano de cozinhar, dependendo de uma situação sociocultural e de história. Por muito tempo o achar que a habilidade feminina de preparar e servir a comida eram tarefas elementares, convencionais e prosaicas, e, por conseguinte, bastante comum no ato de cozinhar em dadas sociedades.

Assim, "as práticas culinárias se situam no mais elementar da vida cotidiana, no nível mais necessário e mais desprezado" por muito tempo "quase todas as mulheres têm que cozinhar quer só para as suas necessidades, quer para alimentar os membros da família e seus convidados ocasionais" (GIARD, 2000, p. 218).

Ou nesse sentido,

[...] em cada caso cozinhar é o suporte de uma prática elementar, humilde, obstinada, repetida no tempo e no espaço, com raízes na urdidura das relações com os outros e consigo mesmo, marcado pela vivência familiar e pela história de cada uma, solidária das lembranças de infância como ritmos e estações. (GIARD, 2000, p. 218 - grifo do autor).

Para poder entender o léxico de origem étnico-cultural dessas práticas culinárias é preciso vivenciar as lembranças pessoais de escutar a voz de mulheres quando elas em suas interlocuções denominam o seu modo de cozinhar, de organizar essa forma de fazer essa prática de cozinhar por meio de sua própria linguagem, quer seja descrever através de suas palavras, de inflexões de suas vozes e do ritmo de suas enunciações.

Para tanto, referencia-se o léxico a partir dos estudos de Chomsky e Lasnik (1995), quando citam que o léxico é um repositório de todas as propriedades idiossincráticas de itens lexicais individuais, sendo que essas propriedades incluem a representação da forma fonológica de cada item, a especificação de sua categoria sintática e suas categorias semânticas.

De acordo com os autores, o léxico é um componente gramatical no qual se encontram as informações (de categorias e de seleção) de natureza fonológica, sintática e semântica sobre os itens lexicais individuais. Ainda, "pode-se dizer que o léxico é o dicionário da gramática: as regras desta manipulam os itens lexicais, fazendo um uso crucial da informação aí contida" (RAPOSO, 1992, p. 89), ou seja, o léxico da gramática no processo mental do indivíduo.

As descrições sobre questões lexicais podem ser analisadas sob aspectos envolvendo nominalização, como também a subcategorização verbal. 
Pode ser "[...] definido como estudo da estrutura interna da palavra e/ou de suas variações de forma, a Morfologia se confronta com problemas de definição de objeto, dada a múltipla pertinência da palavra como unidade lexical, gramatical, fonológica, etc." (BASÍLIO, 1999, p. 54).

Quanto ao desenvolvimento de estudos descritivos sobre "a nominalização, assim como a preocupação com a questão da flutuação de categorias lexicais" sobre o português falado há "uma preocupação cada vez maior com a questão da relevância do fator semântico nos processos de formação de palavras, a qual não era devidamente reconhecida" (BASÍLIO, 2006, p. 473), pelos estudiosos da linguagem.

De acordo com essa discussão, destaca-se o fator semântico nos processos de formação de palavras sob um enfoque de funções extragramaticais, quando de peculiaridades do léxico do português falado. Por conseguinte, o papel da nominalização na construção de itens lexicais com função expressiva pode surgir em interlocuções de enunciados dos falantes. Esse processo lexical com função expressiva no falar português é constante, quer seja no cotidiano, no sentido pejorativo, de humor e de forma ridícula, sendo uso constante em comunidades interétnicas, como nessa de línguas em contato alemão-português.

Quando, porém, se descrevem itens lexicais sob condições socioculturais e de origem étnica, há sempre um estranhamento latente enquanto processo de formação fonética e morfossemântico do léxico utilizado pelos falantes.

Por conseguinte,

Os critérios de aceitabilidades via de regra se alteram e se especificam, como efeito direto da própria consciência da especificidade do tipo de discurso; mas isto não altera as condições de produtividade dos processos envolvidos. Já o discurso falado coloquial dialogado utiliza outro instrumento, a construção interativa; e não permite, em geral, a elaboração mediada, o que certamente delimita o tipo e prejudica a freqüência de operação de construção lexical. (BASÍLIO, 1999, p. 59-60).

Tem-se conhecimento da não aceitabilidade de certas construções lexicais em comunidades de falas interétnicas, quando há evidências sobre os deslizes verbais e de nominalização. Para alguns estudiosos da norma culta, isso não é tão relevante para o acesso lexical na produção da fala porque o fato de falantes poderem, eventualmente, formar palavras em sua língua é bastante conhecido e não é controverso. A questão aqui, neste estudo, é o que 
os falantes fazem habitualmente e, portanto, como se caracteriza a fala no que mostra a construção de transferências de itens lexicais da língua alemã no léxico do português.

Os estudos entre condições de produtividade e condições de produção do léxico é mostrado por Basílio quando

As condições de produtividades referem-se a elementos ou fatores que especificam processos de formação de palavras e determinam sua esfera de aplicação a tipos de base. Assim, as condições de produtividade pertencem ao campo do conhecimento lexical e definem a classe das construções morfossemânticas possíveis no léxico da língua. Condições de produção, por outro lado, referem-se a fatores que favorecem, dificultam ou impedem a operação de processos de formação de palavras em situações específicas. Incluem-se, dentre as condições de produção, fatores fonéticos, paradigmáticos, pragmáticos, discursivos e assim por diante. (BASÍLIO, 2006, p. 474-475).

É a partir das condições de produção em situações específicas de construções lexicais de uso pragmático que se pretende analisar os itens lexicais do ato de cozinhar no dia a dia das mulheres de descendência alemã que transferem as palavras e o seu significado para o português brasileiro no decorrer do ato de fala.

A língua alemã é muito rica em palavras compostas e expressões linguísticas, permitindo infinitas combinações de itens lexicais e, consequentemente, oferece um campo extremamente fértil para a formação e a construção morfossemânticas possíveis quando do processo de contato linguístico com o português, quando alguns elementos são transferidos e outros reproduzidos por extensão dos traços fonéticos e semânticos através de recursos dos atos de fala.

Mesmo que este estudo sobre o fator semântico-pragmático no processo de formação lexical seja, provavelmente, uma abordagem historicamente minoritária e marginalizada pelos estudiosos da gramática normativa, mostra-se um pequeno corpus de dados de uma delimitação de unidades lexicais na especificidade de variação linguística. 


\section{As expressões lexicais do falar diglóssico alemão-português}

O fenômeno de alternância lexical semântico-pragmático de dois sistemas de usos linguísticos, manifestando-se no linguajar do dia a dia de descendentes de alemães, com fortes marcas idiossincráticas, em comunidades bilíngues, quando os falantes, em suas interações comunicativas, são solidários, e usam, espontaneamente em seu cotidiano, traços linguísticos (fonológico, morfossintático e semântico) emprestados de uma para a outra língua.

Nessa comunidade de fala ainda há uma variedade diglóssica suprarregional, denominada de Brasildeutsch, considerando os traços de contato linguístico da variável padrão alemã, mais os seus diferentes dialetos locais e regionais em contato com o português bidialetal. O grupo de descendentes alemães na comunidade reconhece o falar alemão como heterogêneo, quer seja em uma conjunção de falares familiar, quer seja social e geograficamente diferenciado.

Esse fenômeno de uso linguístico acontece pela comunicação oral do falante, quando o mesmo transfere linguisticamente itens lexicais da língua materna vernácula para a língua nacional, sob um processo lexical de informações fonológicas, morfossintáticas e semânticas de dois códigos da variante tipo 'B' do Brasildeutsch, quando esses descendentes estão bem socializados em suas comunidades de fala, como no caso nesta região do oeste paranaense, quando mesclam os traços fonéticos, prosódicos, gramaticais e semântico-pragmáticos dos dialetos regionais e locais da língua alemã no falar do português.

Nos estudos de Heye (2006) e de von Borstel (2011) são apresentados e discutidos que o Brasildeutsch assume uma dupla função em situação de diglossia, como variante intermediária e, essa funciona como uma variedade 'A', que se aproxima à variável do alemão padrão em comunidades com pouca escolarização da língua alemã. Por outro lado, o Brasildeutsch funciona também como variedade 'B' com traços do falar Hunsrückisch ou Plattdeutsch em comunidades com grau de escolaridade maior da língua alemã.

De acordo com as reflexões teóricas dadas por Heye $(1986,2006)$, e, pela exemplificação de enunciados por falantes do falar alemão pode-se dizer que, no grupo da comunidade de fala alemão-português de Marechal Cândido Rondon, ainda se manifestam nas interlocuções dos falantes bilíngues alguma dessas variantes de diglossia do tipo $(+\mathrm{B} /+\mathrm{D})$ - mais bilinguismo/ mais diglossia -, sendo a variedade 'A' do Brasildeutsch com traços formais 
do alemão padrão e a variedade 'B' do Brasildeutsch com traços do dialeto regional Hunsrückisch (Francônio, alemão suíço e suábio), com traços do dialeto regional do Plattdeutsch (Pomerano, Vestfaliano, Deutschruss), com o português.

De fato, esse caráter do falar alemão-português nesse grupo de falantes bilíngues, segundo estudos de von Borstel (2011), pode se dizer que vem a ser uma situação de 'triglossia' de Brasildeutsch (B) + Hochdeutsch (A') + Português (A“). Isso ainda se manifesta nas situações enunciativas desses falantes de descendentes teuto-brasileiros.

Para Heye (2006), a presença dessa variedade intermediária do tipo do Brasildeutsch é bastante rara e, com o passar do tempo, essa variedade pode desaparecer e/ou se superpor ao falar Hunsrückisch ou Plattdeutsch, no sul do Brasil.

O termo comunidade de fala (originalmente utilizado por Hymes, em 1967, como speech community), quando o uso de linguagem é conceituado como formas externas de regulamentação da comunicação verbal. Os eventos de fala não são considerados o sistema, e sim o ato de fala, em suma, o uso pragmático na interação comunicativa entre os usuários de um determinado grupo sociolinguístico plurilíngue.

Em eventos de fala, em comunidades de falantes de língua alóctones, as transferências linguísticas, as unidades lexicais arcaizantes e informais da língua materna vernácula de origem étnica/cultural surgem de forma espontânea nas interlocuções dos falantes.

Como foi apresentado e analisado em situações enunciativas do Brasildeutsch, nos estudos de von Borstel (2011), quando há a transferência do conteúdo fonético e semântico de alguns verbos da língua alemã, isso quando os falantes bilíngues da variante tipo 'B' do Brasildeutsch transferem esse conteúdo semântico do verbo para o português, como no verbo kriegen "receber, obter" para o verbo ganhar "adquirir, obter de forma vantajosa ou proveitosa" (HOUAISS; VILLAR; FRANCO, 2001, p. 1426). Isso se manifesta nas interlocuções entre os jovens como entre os adultos e os idosos na comunidade de Marechal Cândido Rondon e nas comunidades do falar alemão-português na região oeste do Paraná. Assim, eles utilizam a expressão "Eu ganhei um resfriado" ou "Eu ganhei uma gripe". Exemplifica-se com o enunciado de uma entrevistada: Mein Kind, ich hab die Grippe gekricht (Minha 
filha, eu 'ganhei' a gripe) - (E.: LB, em MCR, 2010). O fato é que o recurso semântico do verbo gekricht é transferido para o verbo 'ganhar' no português, de uma informação semântica do falar do alemão para uma (re)interpretação pragmática para o português, como se o sintagma verbal 'ganhar' herdasse esses traços fonéticos, morfossintáticos e semânticos dos imigrantes e seus descendentes para o falar alemão-português.

A esse propósito, Weinreich cita que:

Ao nível da fala, a interferência é resultado do conhecimento de outra língua. Quanto ao nível da língua, a interferência ocorre freqüentemente na fala do bilíngüe, tornando-se hábito e se estabiliza - seu uso não depende mais do bilingüismo. Para o falante, pode ser um empréstimo herdado, que ele não reconhecerá como tal. (WEINREICH, 1953, p. 11)

Nesse sentido, exemplifica-se com os estudos de Fausel (1959, p. 111), quando mostra a transferência do conteúdo semântico da expressão no português "vou me cobrar" (vou me lembrar) para a língua alemã, como em "Ich werde mir kobrieren." (Eu vou me lembrar.) - (E.: DS, em MCR, 2010), mostrando uma informação do conteúdo fonético, morfossintático e semântico do verbo da língua portuguesa utilizando recursos da conversação pragmática para o falar dialetal do alemão.

Ou, ainda, a pesquisa desenvolvida por Pereira (2009, p. 20), na comunidade rural de descendentes de alemães de São Pedro, Missal, PR, quando os falantes utilizam a forma do verbo ganhar no sentido do verbo ter e sentir, como em "Minha avó ganhou um ataque" e "Ela ganhou dor de estômago".

Nas interações comunicativas do cotidiano em falantes de descendentes alemães na região sul do país, observou-se o uso dessas expressões linguísticas no português, tendo origem no bilinguismo societal do falar da língua alemã e seus dialetos regionais.

Nos estudos de Heye (2006), o uso do falar alemão foi caracterizado pela presença de duas variantes, o alemão padrão, enquanto variedade A(lta), e uma variedade B(aixa) que se manifestava, de acordo com a origem dos descendentes dos imigrantes alemães, ou como Hunsrückisch ou como Plattdeutsch. Esta última formada por um conjunto de dialetos do norte da Alemanha, com uma extensão que ia da fronteira da Holanda até o que hoje é a Polônia (a região do 'Pomerano'). Esse conjunto de dialetos se enquadra no que se rotula de Niederdeutsch ou Plattdeutsch. A outra variedade tipo 
'B', do Hunsrückisch, precisa ser vista como uma categoria que engloba uma grande variedade de dialetos alemães de diferentes regiões, que vão do próprio Hunsrück, no centro da Alemanha, até a Suíça e o norte da Itália, formando, desta maneira, uma categoria pouco especificada e uniforme. Ao longo dos anos, na região sul do Brasil, com o aumento do nível de escolaridade nas respectivas comunidades de descendentes de alemães e através da convivência diária com falantes de ambos os grupos de dialetos dentro das mesmas comunidades, surgiu uma variante intermediária que foi denominada por Heye $(1978,1986)$ de Brasildeutsch e que assume uma dupla função dentro do sistema diglóssico.

\section{O falar Brasildeutsch em enunciados no ato de cozinhar}

A partir de situações enunciativas do ato de cozinhar no cotidiano (é aquilo que é dado e que se compartilha a cada dia com os seus familiares, amigos e vizinhos) apresentam-se os itens lexicais da variante do tipo 'B' do Brasildeutsch, tendo origem nas formas dialetais do Hunsrückisch e/ou do Plattdeutsch:

Keschimia - Na língua alemã Quark [kvart] - requeijão (HOEPMER, KOLLERT; WEBER, 2001, p. 1006). Keschimia ou Käseschmie(r) na variante tipo 'B' do Brasildeutsch - denominado de ricota: queijo de consistência macia um pouco úmida para seca, feito com leite coalhado sem maturação alguma, na região é denominado de 'requeijão' pelos descendentes de alemães, esse queijo de consistência macia seca levemente úmida é misturado com nata (hoje, muitos, já misturam com iogurte natural) e uma pitada de sal, uma pasta cremosa para passar sobre a fatia de pão "Ich werde eine Stückmilhebrot mit Keschimia essen...” (Eu vou comer uma fatia de pão de milho com requeijão) - (E.: LB, em MCR, 2010).

Stinkkäse ou Stinkkese (Kochkäse, um tipo de queijo cozido com odor e cheiro forte). O modo de fazer, segundo as descendentes de alemães, é deixar coalhar o leite, depois pegar a coalhada, dá-se leve esquentada, colocando em um pano branco até que a ricota esteja úmida para seca, guardando por alguns dias em um pote fechado, quando se dá o odor forte da ricota ou segundo os falantes o "queijo fedorento". Para transformar em Stinkkäse é necessário colocar um pouco de manteiga em um recipiente, em seguida colocar o "queijo fedorento" para cozinhar até ficar cremoso, depois do processo 
de esfriamento, a pasta cremosa está pronta para passar sobre a fatia de pão de Schartzbrot (Kastenbrot ou Mischbrot - pão de centeio ou integral) ou no de Milhebrot (Maisbrot ou Mischbrot - pão de milho) para comer - "Tante Christa, ich werde eine Stückmilhebrot mit Stinkküse essen ..." (Tia Christa, eu vou comer uma fatia de pão de milho com queijo fedorento) - (E.: LW, em MCR, 2011).

A forma dialetal utilizada pelas entrevistadas nas interações comunicativas dessas descendentes de alemães manifestam-se através de enunciados sócio-históricos em suas vivências a partir de histórias familiares e de amizade da esfera privada (na cozinha quando da arte da alimentação) para a esfera pública, apresentando itens lexicais de uma forma linguística fonética, morfossintática e semântico-pragmática emprestados que apresentam a construção da formação lexical da língua alemã, adaptando-se ao significado, para poder adequar-se à realidade cultural, ao ambiente e aos costumes na comunidade de teuto-brasileiros.

Essa incorporação linguística na designação terminológica por uma forma nominalizada é utilizada como uma a referência anafórica ao sintagma verbal e nominal correspondente, de modo que os falantes descendentes de alemães na comunidade de fala manifestam a variedade 'B' do Brasildeutsch com traços do dialeto regional Hunsrückisch (Francônio, alemão suíço e suábio), com traços do dialeto regional do Plattdeutsch (Pomerano, Vestfaliano, Deutschruss), com o português.

Esses dados linguísticos são incorporados entre a palavra e o afetivo-emocional de aspectos da cultura sócio-histórica na comunicação entre as pessoas sob uma concepção semântica e pragmática.

\section{Considerações Finais}

As expressões linguísticas do Brasildeutsch utilizadas nas interlocuções do ato de cozinhar de falantes bilíngues, na fala dos descendentes de alemães é retratada pela memória histórica de experiência de vida. É aquilo que faz lembrar e recordar a partir da e pela linguagem desde a infância através de relatos de geração a geração, dando significação aos fatos do cotidiano, incorporando as suas vivências, utilizando as palavras herdadas de seus antepassados, por conseguinte, a língua de herança de uma origem étnica/cultural. 
Essa transformação linguística se manifesta pela internalização da linguagem verbal, quando é demonstrado pelo aspecto semântico (a representação do significado) e pelo pragmático (a representação do interpretativo e ou (re)interpretativo de fatos de experiências na palavra do cotidiano), a partir da palavra em situações enunciativas de falantes bilíngues societais quando o ser, falar e fazer caracterizam o diferente, em uma dada comunidade de fala, em suas interações comunicativas quando são compartilhadas entre os descendentes nas atividades do cotidiano.

\section{Referências}

BASÍLIO, Margarida M. de P. A morfologia no Brasil: indicadores e questões. D.E.L.TA. v. 15, n. Especial, p. 53-70, 1999.

A estruturação do léxico: na descrição do português brasileiro. In: CARDOSO, Suzana, A. M.; MOTTA, Jacyra A.; SILVA, Rosa V. M. (Orgs.). Quinhentos anos da história da linguística do Brasil. Salvador: Secretaria da Cultura e Turismo do Estado da Bahia, 2006. p.463-485.

CHOMSKY, Noam; LASNIK, Howard. The theory of Principles and Parameters. In: (Ed.). The minimalist program. Cambridge: The Mit Press, 1995. p. 425-508.

FAUSEL, Erich. Die deutschbrasilianische sprachmischung: probleme, vorgang und wortbestand. Berlin: Erich Schmidt Verlag, 1959.

GIARD, Luce. Cozinhar. In: CERTEAU, Michel de; GIARD, Luce; MAYOL, Pierre. (Orgs.). A invenção do cotidiano: 2. Morar, cozinhar. Tradução de Ephraim F. Alves e Lúcia E. Orth. Petrópolis, RJ: Vozes, 1996. p.211-298.

HEYE, Jürgen. Sociolingüística. In: PAIS, Cidmar T. et al. (Orgs.). Manual de lingüística. Petrópolis, RJ: Vozes, [1978]. 2. ed. São Paulo: Global Ed., 1986. p. 203-237.

. Sobre o conceito de diglossia. In: GORSKI, Edair M.; Coelho, Izete L. (Orgs.). Sociolingüística e ensino: contribuições para a formação de professores de língua. Florianópolis: Ed. UFSC, 2006. p.69-83.

HOEPNER, Lutz; KOLLERT, Ana M.; WEBER, Antje. Langenscheidt: taschenwörterbuch portugiesisch. Berlin und München: Lagescheidt Verlag, 2001.

HOUAISS, Antônio; VILLAR, Mauro de S.; FRANCO, Francisco M. de M. Dicionário Houaiss da língua portuguesa. Rio de Janeiro: Objetiva, 2001.

HYMES, Dell. On communicative competence. In: PRIDE, J. B.; HOLMES, J. (Eds.). Sociolinguistics, Harmondsworth. England: Penguin Books, 1967. p. 269-294.

PEREIRA, Maria Ceres. Cenário de bilingüismo e de transculturalidade no oeste paranaense. In: SELLA, Aparecida F. (Org.). Percorrendo estudos linguísticos e práticas escolares. Cascavel: EDUNIOESTE, 2009. p.13-26. 
RAPOSO, Eduardo Paiva. Teoria da gramática: a faculdade da linguagem. Lisboa: Ed. Caminho, 1992.

VON BORSTEL, Clarice N. A linguagem sociocultural do Brasildeutsch. São Carlos: Pedro \& João Editores, 2011.

WEINREICH, Uriel. Languages in contact. New York: Linguistic Circle \& The Hague, Mouton, 1953.

Recebido para publicação em 19 jul. 2011. Aceito para publicação em 20 ago. 2011. 